\title{
Exploring Multiculturalism as a Dynamic Factor for Spurring the New Economy, Particularly Present Within Port Cities
}

\author{
Luana Parisi ${ }^{1,}$, John Eger ${ }^{2}$ \\ ${ }^{1}$ School of Architecture, Computing and Engineering, University of East London, London, United Kingdom \\ ${ }^{2}$ College of Professional Studies and Fine Arts, San Diego State University, San Diego, United States
}

\author{
Email address: \\ parisi2@uel.ac.uk(L. Parisi),jeger@mail.sdsu.edu (J. Eger) \\ ${ }^{*}$ Corresponding author
}

\section{To cite this article:}

Luana Parisi, John Eger. Exploring Multiculturalism as a Dynamic Factor for Spurring the New Economy, Particularly Present Within Port Cities. Urban and Regional Planning. Vol. 5, No. 4, 2020, pp. 114-121. doi: 10.11648/j.urp.20200504.13

Received: November 20, 2020; Accepted: December 7, 2020; Published: December 16, 2020

\begin{abstract}
Cities are widely recognized as the preferred places for cultural production and interactions, with their ability to agglomerate high-skilled workers and talented people, and to host services and knowledge infrastructures connected through formal and informal networks. They stand at the intersection points of both physical connections, including passenger travels and trade of goods and non-physical relations. The paper starts from the acknowledgment that innovation comes out as a consequence of these networks, triggering the economic growth and making cities attractive and competitive. It will then investigate the role of the human capital, as the current best productive asset, that acquires a new value in virtue of the social capital. The aim is to demonstrate that multiculturalism is an innovative, dynamic factor for development necessary for cities to thrive, that is particularly present within port cities. These nodes of transportation and relational networks, in fact, are embedded into several activities that go far beyond their boundaries and emerge as places of conflicts, but also of innovation and progress. In order to support the discussion, this contribution will explore the Innovation District of Boston as a significant case study, since, with its strong multiculturalism within a port environment that is deeply changing, the area is favoring the new economy of innovation. The results of the study will highlight the challenging character of stressing multiculturalism in a general climate of mistrust, intolerance and fear and will recognize the fact that in the era of the human capital there is an important element linked to connections, both physical (transportation links) and relational (social capital), that have the ability to transform the look of cities, opening up new opportunities to grow and use the human capital in unexpected ways. A set of possible future scenarios of policies will be proposed as well, considering the diversity added value and the prioritization of physical and relational connections.
\end{abstract}

Keywords: Innovation Economy, Multiculturalism, Human and Social Capital, Port Cities

\section{Introduction}

Under the hegemony of the new globalized economy, the world map has been redrawn in a way never envisioned before. The net effect of these changes is that there are no longer the traditional barriers and boundaries in doing business, since each individual is suddenly able to compete with any other at any time. The economic geography that emerges depends mainly on highly specialized professional activities, geographically concentrated in urban contexts [51] and strictly dependent on the innovation paradigm.

Over the last decades, in fact, innovation has become essential within the economic growth pattern, moving at the center of the stage of policy makers worldwide.

This unusual social and economic perspective, where innovation is vital for boosting the economic development, reducing disparities, but also for making cities attractive and competitive [15], allows to investigate new means to trigger it, setting aside the classical industrial framework that dominated the past development processes.

The roots of the innovation economy have to be traced in the work of the economist Joseph Schumpeter, who first acknowledged the pivotal role played by innovation in generating economic prosperity, by means of the so-called "creative destruction", a "process of industrial mutation that incessantly revolutionizes the economic structure from within, 
incessantly destroying the old one, incessantly creating a new one" [53]. Afterwards, the Neoclassical Growth Model further supports the connection between innovation and economic growth [56].

More recently, the Organization for Economic Co-operation and Development (OECD) recognized in the promotion of innovation the main engine for reducing inequalities and improving the economic growth also in deprived contexts [41]. Besides this, the World Bank has seen innovation as the driver of socioeconomic progress, through the triggering of wealth and skilled jobs, the urban systems development and the increase in the competitiveness levels [58].

Finally, the Lisbon's strategy introduced the issue of innovation within the territorial productive system [14].

Within the "innovation-based growth theory", wealth is no longer dependent on the usual factors of production, such as capital, labor and natural resources, yet, is engendered by knowledge and technological and scientific improvements [2].

This approach puts knowledge and information at the center of the stage for tailoring successful strategies aimed at boosting growth and increasing competitiveness.

In this regard, a conspicuous number of scholars acknowledged the importance of proximity in achieving the competitive advantage [44], highlighting the propensity of different actors and firms to locate close to each other, in order to "innovate at a quicker rate, sharing technologies and knowledge easier" [23]. Indeed, "the ability for small firms to generate ideas and mingle with larger firms who have the access to capital and the ability to scale and grow these ideas is imperative in entrepreneurial fields" [23].

This fertile environment called innovation ecosystem is vital for spurring economic growth by means of innovation. It comprehends a mix of innovations and communities, where "the principal actors are usually for-profit firms, universities and other public and private specialist research organisations and knowledge-based consultancies" [38].

With their ability to agglomerate high-skilled workers and talented people, and to host services and knowledge infrastructures, as universities and research centers [13], connected through formal and informal networks [40], cities reveal themselves as the spots where progress and economic development occur [24].

They stand at the intersection points of both physical connections, including passenger travels and trade of goods and non-physical relations, including the production of services [12]. As a consequence of these urban flows, it comes out the innovation paradigm. This sort of urbanization process of innovation has overcome the model that dominated the past 50 years, made of "suburban corridors of spatially isolated corporate campuses, accessible only by car, with little emphasis on the quality of life or on integrating work, housing, and recreation" [30].

The paper aims at pointing out that multiculturalism is an innovative, dynamic factor for development necessary for cities to thrive. This factor is particularly present within port cities. These crossroads of different cultures and ideas, which are embedded into several activities that go far beyond their boundaries, in fact, emerge as places of conflicts, but mainly of innovation and progress.

This contribution is articulated into three main sections: the first investigates multiculturalism and the role of the human and social capital; the second one explores port cities environment as multicultural hubs; the third one will present some insights from the Innovation District of Boston as a significant case study and the last one will present the results of the study, proposing also a set of possible future scenarios, considering the diversity added value and the prioritization of physical and relational connections.

The Boston Innovation District represents an emblematic case study since with its strong multiculturalism within a port environment that is deeply changing, the area is favoring the new economy of innovation, through a new generation of urban planning tools promoted by the City.

\section{Multiculturalism and the Role of Human and Social Capital}

As we have seen, the 21 st Century opened a challenge necessary for cities to succeed. They need, in fact, to become creative, finding new ways to attract, nurture and retain talents by setting up good living and working conditions within rich ecosystems of innovation based on an atmosphere of tolerance able to facilitate the flows of knowledge.

Thus, knowledge-intensive industries and talents "are extensively seen as the primary factors needed to improve the welfare and competitiveness of cities" [65].

It comes out a global cutthroat competition among talents [51] that colonize a few cities in the World. Consequentially, the human capital emerges as the best productive asset. This is in line with a sound body of knowledge, including the works of Marshall [35], Shumpeter with its theory of economic development [53] and Jacobs [27], who stated that the economic development relies upon the human capital growth. Additional evidence is provided by Romer and Lucas, who, against the neoclassical growth models, affirm through the Endogenous Growth Theory that the economic growth is internally generated and is essential to invest in human capital, innovation and knowledge [34; 49].

Currently, the human capital acquires a new value in virtue of the social capital, namely the network of relationships that allows the mingling of information and knowledge flows. As a matter of fact, if before the social capital was considered the output of institutions and firms, today it is among the main inputs for the development process [21].

The consolidated social interactions between competitive clusters of human capital spread within metropolitan areas [50], need the geographical proximity as a "prerequisite to make learning and innovation successful" [8], stressing the exchange of knowledge, facilitated by formal and informal relations.

Thus, besides the advantages of the agglomeration 
economies, such as the creation of a pool of skilled labors [35], and the competitive advantage that comes out [45], the geographic "clusterization" phenomenon is crucial for the knowledge sharing process amongst the networks of actors living in close proximity $[17 ; 45]$.

In sight of this, giving the importance of the human capital, the social interactions and the current competition for talents, cities need to be nurtured by multiculturalism in order to thrive.

The multicultural society has as its direct phenomenon cultural diversity [29] with its positive influence on the social capital [43], being a "source of exchange, innovation and creativity" [59].

It gives a great contribution to the innovation process [43] and the quality of life, preserving the identity of places, the institutions and the social structure [64], reflecting people with their values and behaviors and "the way of life" of places [31].

Multiculturalism implies the development of pluralism and mutual Tolerance [29], where the latter one, with its "live and let live" ethos, is among "the three T's" of economic development together with Talent, comprehending the better educated and skilled people, and Technology, that includes the necessary infrastructures for fueling an entrepreneurial culture [18].

Following this framework, the mobility trends of the last years, being different from the traditional migrations, open up new flows and take on new meanings [52].

They are partly due to the specific problems of each Country and partly to the contemporary ease of mobility and contribute to layer and blend cultures, ideas and technologies, creating "deeply textured, economically and culturally rich continent now so appealing to those seeking new lives" [1]. They bring "considerable advantages for organizations and cities in terms of increased innovation, productivity and ability to solve problems" [9]. The diversity added value has significant long-term implications for the economic growth and the competitiveness of a Country [22] and for designing urban policies, "since involving people of diverse backgrounds in policy design increases effectiveness" [9].

Several superdiverse cities (e.g. London and New York) use these features to plan their own development transcending "national, faith and ethnic boundaries" and recognizing specific needs at the same time [62].

All the concepts above can be summed in the following figure, where migration and population diversity, together with the networking process and new economic activities have the ability to raise the cross-sectoral collaborations and cross-fertilization potential, which is a form of collaboration, occurring when "collaborators make efforts to share and exchange skills as well as work across professional boundaries in ways that may readdress or redraw the boundaries themselves" [39].

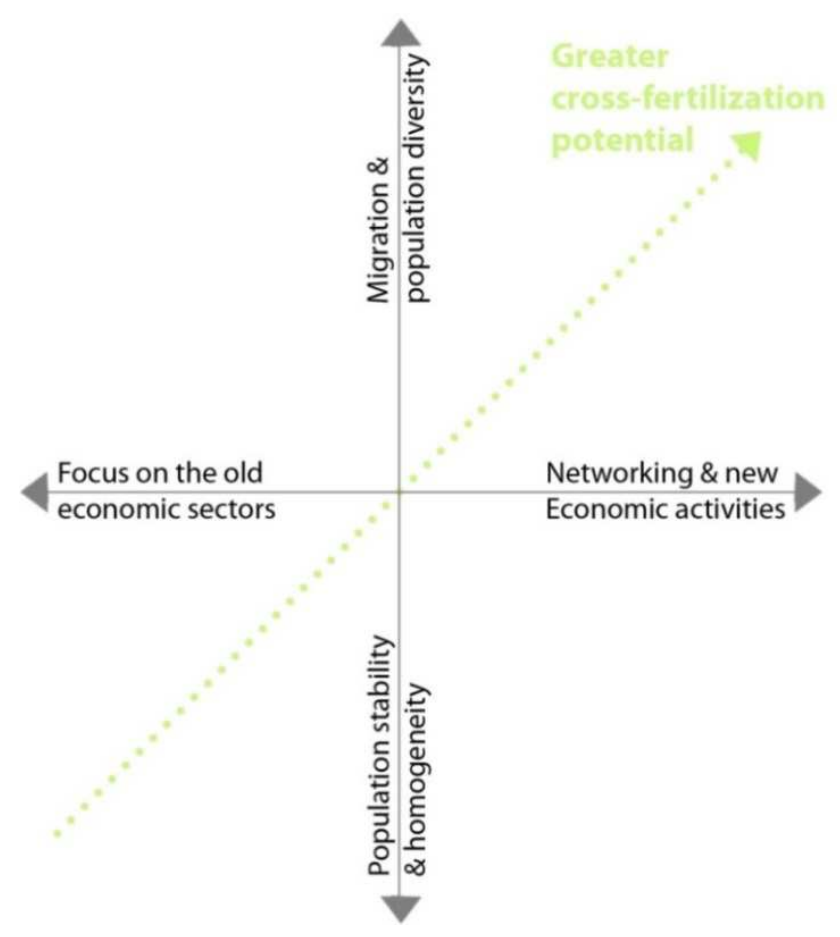

Figure 1. The cross fertilization potential trend based on the Cultural Shift \& Population Movements. Source: Retrieved and adapted by the authors from Landry, C. [31].

The multiculturalism emerges as an innovative, dynamic factor for the development, so that it becomes necessary the support to the social, cultural, ethnic and skill diversity within the innovation economy, by adopting an intercultural approach for facilitating the dialogue and mutual understanding [64].

\section{Port Cities as Multicultural Hubs}

So far, it arose that multiculturalism is for cities an important source of creativity [33], allowing to people to work together, collaborate and generate new ideas, providing an opportunity for getting new perspectives and thoughts, favoring also their creative dissemination [33]. As Jacobs stated, in fact, "great cities are places where people from virtually any background are welcome to turn their energy and ideas into innovations and wealth" [26]. Thus, it can be considered the technology of a very different global economy, where ideas represent the new wealth [47]. This explains why it has an important role in fueling innovation and urban growth [26].

This approach to economic development more people-oriented finds a fertile breeding ground within the environment of port cities. These spots transformed over time the look of cities, offering privileged links to the interior [4], facilitating international trade and energizing the flows of goods and services around the world [37], allowing to trigger positive processes of local developments and changes of both the natural and the built environment. Moreover, migration and diversity have the potential to become an added value able to reinforce the global positioning and economy of cities [25]. 
The activities in which they are embedded go far beyond their physical boundaries [12].

Besides offering important trading economy, representing the dynamic knots of the new economic geography made of a marked East-West orientation of the world's markets and the key hubs of the Global Value Chains [19], competing with one another globally, they are also "better suited to take part in a regional system", holding "the key to the region's future economic prosperity" [54].

There is a further developmental component that can be found mainly in global gateway seaports, namely the fact of being global cities, acting as "portal and stage for world connectivity", attracting "a genre of global-aspiring urban professionals" [5] and registering strong presences of foreign-born people. This is in line with their historical feature of being gateways of immigrants [55; 4].

Currently, about 3 billion people (approximately half of the world's population) lives within 200 kilometers of the coastline, with the numbers expected to double [10], presenting a density of population that is twice the world's average [60].

The overlap of the historical layers, made by the continuous exchanges of people and goods and mishmashes between cultures, has pushed over time on their multiculturalism [12] and the "live and let live" philosophy, so that the mutual Tolerance is more developed than the other contexts [54].

Not surprisingly, ports emerge as the "primary platforms in the knowledge economy based on preexisting resources", able to "achieve a sustainable balance which fosters development"

\section{LOCATION}

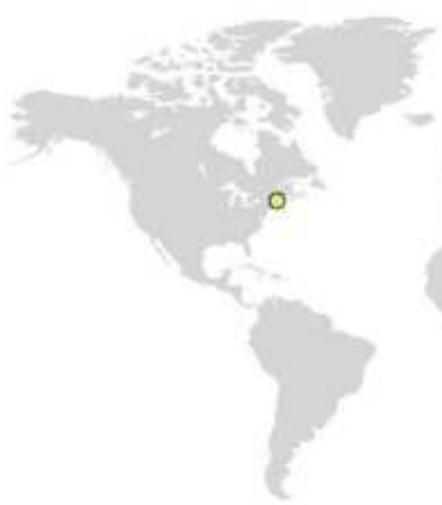

POPULATION

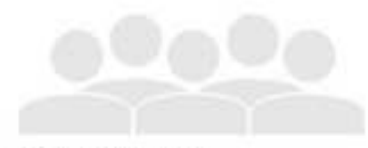

667,137 inhabitants

NEW ECONOMIC MODEL
[12].

With their important "history of sharing ideas on a regional, national and international level" [46], they can unfold new models of innovation and determine in such a way the research orientations [42]. They are already considered the "spatial clusters for innovation, research and development" [37].

The presence of the infrastructure of the port constitutes a competitive edge for cities, having the ability to "broaden the benefits of innovation", offering the possibility to collaborate more easily and with a broader scenario [57].

These melting pots and crossroads of different cultures and ideas, open to global connections, emerge as the most likely places to accommodate successful development programs, since they got an advantage in the effort to reinvent themselves in view of the new economy.

It becomes necessary to mingle the logistics of ports with the flows of capital of cities, contemplating both the physical connections, including "passenger travel" and "trade of goods" and the non-physical relations [12] which are at the base of the new innovation economy.

\section{The Boston Innovation District as a Significant Case Study}

The city of Boston will now be explored as a significant case study, since, with its strong multiculturalism within a port environment that is deeply changing, is favoring the new economy of innovation.

\section{DIMENSION}

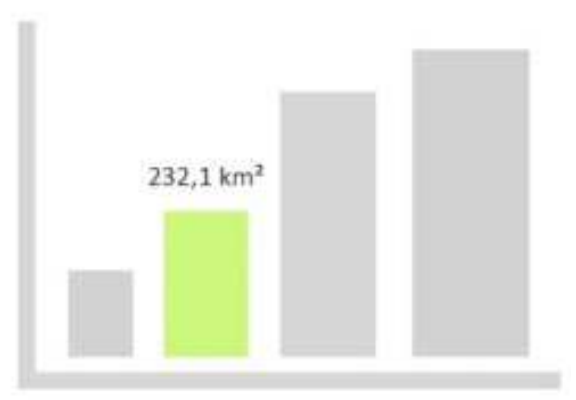

POSITIONING
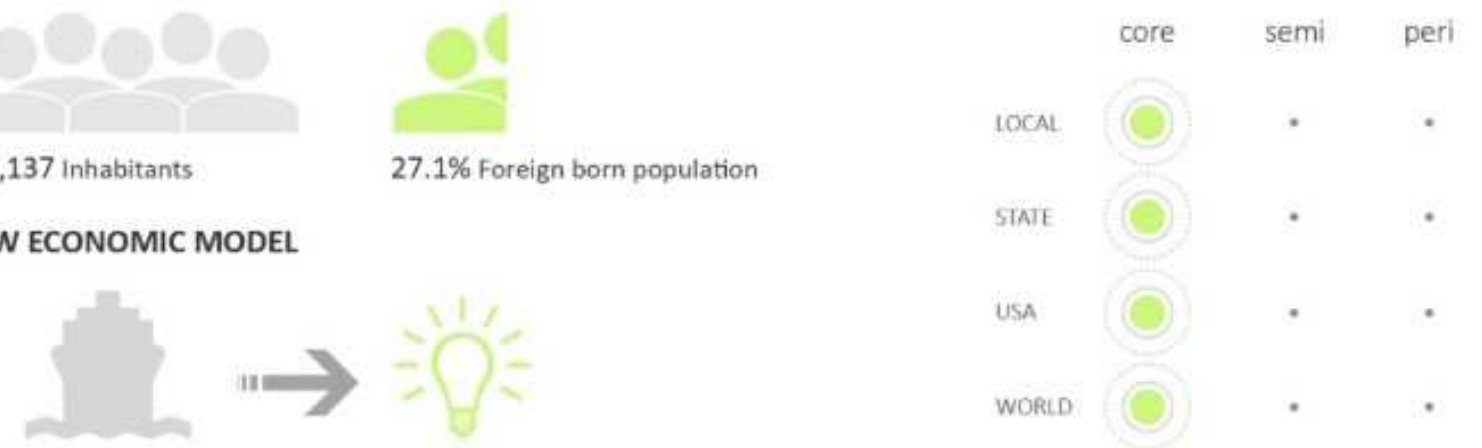

Figure 2. Boston City Framework, including location, dimension, population, positioning and shift of the economic model. Source: Authors'elaboration, 2016. 
Boston is within the top 25 largest cities in the U.S., owing the profile of a city that is growing $(+13,33 \%$ of the population in the last 6 years), but maintains a human-scale dimension (personal communication, June 22, 2016). A report from the Boston Redevelopment Authority points out that in the length of time 2000-2014, there has been an increase in the foreign-born population of $19.2 \%$ [7]. As a matter of fact, with more than a quarter of people born outside America, the city occupies the 7 th position for the share of foreign-born residents among the 25 largest U.S. cities [7]. As we have already seen in the previous sections, this represents a precious source of innovation and economic growth.

Its interculturality depends also on the fact that the city is a mecca for education, being home of 35 colleges, universities and community colleges, that register about 152,000 students from all over the World [6]. As a matter of fact, "the intellectual power here is staggering, with Harvard, MIT, and dozens of other schools making this the academic capital of the world" [20].

Clearly, Boston owes its growth also to the importance of the port, "which is New England's largest seaport" [36] and was among the "world's wealthiest international trading ports" after the American Revolution [32], considered a "thriving shipping area that in the early part of the 20th century received raw materials like wool and leather for local textile factories" [3].

This active freight pole until a few years ago was essentially daily catch and rail yards, used for the transportation of goods. When the industry of shipping declined, most warehouses have been abandoned and the rail yards became huge parking lots valuable for people who had to walk into the nearby downtown neighborhood, which had more expensive parking (personal communication, June 25, 2016).

Then, a series of physical transformation, over time, changed the face of the then-rotted Seaport area. Among them, the move of the John Joseph Moakley United States Courthouse in 1998 [3] and the "Big Dig" project, completed in 2007, which connected the waterfront with both the downtown area and the Logan International Airport [3]. Moreover, a cultural wave hit the area, with the opening of the 65,000 square foot building of the Institute of Contemporary Art (ICA) and the move of one of the largest artist community in New England (personal communication, June 16, 2016). This has had a ripple effect on the opening of new restaurants and the attraction of residents and big multinationals [3], previously located in Kendall Square, in the city of Cambridge (personal communication, June 16, 2016).

In 2008, with the market collapse, there has been a watershed also in the planning regulation of the area. The old planning made by the Boston Redevelopment Authority back in the late ' $90 \mathrm{~s}$, in fact, has been revised and the city changed the zoning of the area in order to accommodate innovation, since previously it did not allow R\&D functions (personal communication, June 16, 2016).

The Public Administration came up with the idea of the Seaport Innovation District with the willingness to bring people in the area and push a mixed neighborhood, with residences, shops, cultural institutions, hotels, open spaces, restaurants and a flourishing working environment (personal communication, June 25, 2016) able to spur a global competition for companies, new ideas and new ways of working, creating new jobs and retaining local talents.

The intent was to "establish an abundance of collaborative open spaces and organizations, including incubators, accelerators, co-working spaces, schools and job training firms advancing specific skill sets for the innovation economy" [61], "fostering collaboration with new workspaces" [23].

The area went from being dominated mainly by the Industrial/Manufacturing sectors (65\%) in the year 2000, to an increase in the office $(+16 \% 2000-2013)$, residential $(+5 \%$ 2000-2013), convention (+5\% 2000-2013) and hotel $(+5 \%$ 2000-2013) uses [36]. The Industrial/Manufacturing/Maritime segments reached the $33 \%$ in 2013 [36]. Thus, port activities and industrial uses are still present, occupying about one third of the waterfront land, supporting "approximately 50,000 jobs [...] with 1,600 companies importing and exporting goods through the port" [36], but the new Innovation District is stimulating the economic growth of the whole city system, becoming an essential engine and catalyst for new companies.

Since it has been launched in 2010, in fact, it allowed to establish more than 200 new companies, creating about 5,000 new jobs [28], targeting mainly young, creative people from different cultural and educational background.

The city tried to attract a community of innovators, through a positive environment able to create a ferment of "creativity and exchange $[\ldots]$, building physical spaces that enabled entrepreneurs to converge during and after work hours became imperative for the public sector" [48].

The intent was to shape an industry-agnostic community, that collaborates and innovates, made of both "established companies and small enterprises" [48], able to exploit and strengthen the existing social, cultural, ethnic and skill diversity.

The "proximity" concept lies behind the program, proving that "people in clusters innovate at a quicker rate, sharing technologies and knowledge easier [...]. The ability for small firms to generate ideas and mingle with larger firms who have the access to capital and the ability to scale and grow these ideas is imperative in entrepreneurial fields" [23].

An ecosystem has been built up, everything from workspaces, that make easy to get a space for working on a startup, which is inexpensive, but allows to interact with people, to public spaces, like District Hall, non-profit organizations, support groups and then co-working spaces and incubators (personal communication, June 25, 2016), that let to about a $40 \%$ of the companies located in the area to share the spaces, using the human capital to generate innovative activities [48].

The idea of implanting an Innovation District machine on Port areas, where port-related activities already moved away or coexist with businesses, help also to connect again the port and the city systems, transcending their boundaries. 
The physical regeneration of the former port area was facilitated by a new generation of urban planning tools focused on innovation promoted by the City and was accompanied by a process aimed at reproducing the serendipity that is behind innovation.

\section{Conclusions and Future Scenarios}

As explained in the previous sections, the new economic geography is based on highly specialized professional activities, geographically concentrated in urban contexts [51]. Accordingly, cities emerge as the spots where innovation, progress and economic development occur [24], able to offer the human, social, financial and physical capital required for succeeding (personal communication, April 13, 2016).

Giving the importance of the human capital, the social interactions and the current competition for talents, cities need the multiculturalism, being a "source of exchange, innovation and creativity" [59], in order to thrive.

Multiculturalism arises as a factor of innovative dynamism particularly present within port cities, which are gateways open to global connections and offer an important "trading economy and a history of sharing ideas on a regional, national and international level" [46].

They emerge as the spatial hubs of transformation in the innovation economy, being as "primary platforms" that, thanks also to preexisting resources, can "achieve a sustainable balance which fosters development" [12].

Thus, in the era of the human capital, there is an important element linked to connections, both physical (transportation links) and relational (social capital). They have the ability to transform the look of cities, opening up new opportunities to develop and grow and use the human capital in unexpected ways.

In a current general climate of mistrust, intolerance and fear, considering the added value of these elements has important long-term implications also for designing more effective urban policies.

Contaminating cities with a diversity agenda and strengthening, at the same time, the physical transportation links, can make the difference.

It is necessary, thus, to establish policies that dedicate funding to the improvement of infrastructures, in order to support the global economic activities linked to innovation [11].

"The first step in this process is prioritizing infrastructure projects that help move goods and people around the world", starting from the infrastructures of ports [11].

The logistic of ports, in this way, mingles with the flows of capital of cities, considering the knowledge and human side of the port city environments.

"Business and civic organizations have two crucial roles to play: first, to advocate for the most effective improvements and second, to build broad-based community and business support for these massive multiyear projects" [11].

Furthermore, strengthening the already existing diverse workforce within port environments requires a strong commitment to advance cultural changes, "underpinned by investment to develop a cohesive set of employment policies and practices" [16].

This answers to ethical, regulatory and economic reasons [63] and regard the social, cultural, ethnic and skill background within the innovation economy context.

For cities to better exploit the advantages of cultural diversity, thus, they need to adopt an Intercultural approach for facilitating the dialogue and mutual understanding [64]. This can be done through intercultural exchange and innovation, to be unlocked by new skills, such as cultural awareness. "The creative challenge is to move from the multicultural city of fragmented differences to the co-created intercultural city that makes the most of diversity" [64].

\section{Conflicts of Interest}

none.

\section{Acknowledgements}

This contribution has been possible thanks to whom gave the possibility to do a research experience at the San Diego State University, allowing to the two authors to get in touch more easily.

The gratitude is extended to all the key informants who have been interviewed in the city of Boston who offered their precious knowledge.

Finally, the authors want to thank the people closest to them, who always give their priceless support.

This research did not receive any specific grant from funding agencies in the public, commercial, or not-for-profit sectors.

\section{References}

[1] Associated Press (2015). How the layering of migrating people and cultures over centuries wrote the story of Europe. Retrieved July 10, 2016, from www.foxnews.com: http://www.foxnews.com/world/2015/10/01/how-layering-mig rating-people-and-cultures-over-centuries-wrote-story-europe. html.

[2] Baily, M., Katz, B., \& West, D. (2011). Building a Long-Term Strategy for Growth through Innovation. Brookings Institution.

[3] Baker, M. R., Vogel, C., \& Doyle, P. (2012). The Rise of the Seaport. Retrieved 2016, from bostonmagazine: http://www.bostonmagazine.com/2012/07/rise-seaport-district -boston/.

[4] Bergquist, J. M. (2008). Daily life in immigrant America, 1820-1870. Greenwood Publishing Group.

[5] Boschken, H. L. (2013). Global Cities Are Coastal Cities Too: Paradox in Sustainability? Urban Studies, 50 (9), 1760-1778.

[6] Boston Redevelopment Authority (2010). Boston by the numbers - Colleges and Universities. Retrieved from bostonplans.org:

http://www.bostonplans.org/getattachment/3488e768-1dd4-44 46-a557-3892bb0445c6/ 
[7] Boston Redevelopment Authority (2015). Boston by the numbers, 2015. Retrieved from https://www.bostonplans.org/getattachment/1 fd5864a-e7d2-4e bc-8d4a-a4b8411bf759

[8] Butzin, A., \& Widmaier, B. (2012). The study of time-space dynamics of knowledge with innovation biographies (No. 07.12). Working Papers on Innovation and Space.

[9] Council of Europe (n.d.). The Intercultural cities network: a learning community. Retrieved October 11, 2016, from rm.coe.int:

https://rm.coe.int/CoERMPublicCommonSearchServices/Disp layDCTMContent?documentId $=0900001680488 \mathrm{e} 90$

[10] Creel, L. (2003). Ripple effects: population and coastal regions (pp. 1-7). Washington, DC: Population Reference Bureau.

[11] Delaney, D. (2015). San Diego's Global Trade and Investment Initiative. $\quad$ Retrieved 2017, from http://www.burkco.com/218-insights/

[12] Derudder, B., \& Witlox, F. (2016). Hub cities in the knowledge economy: seaports, airports, brainports. Routledge.

[13] Dovey, J., Pratt, A. C., Moreton, S., Virani, T., Merkel, J. \& Lansdowne, J. (2016). The Creative Hubs Report 2016. Creative Hubs: Understanding the New Economy. City University of London.

[14] EU Commission. (2012). Guide to Research and Innovation Strategies for Smart Specialisations (RIS 3).

[15] EUROCITIES. (2016). Cultural and creative industries as motor for urban regeneration and economic vitality. Retrieved 2016, from Culture For Cities and Regions: http://www.cultureforcitiesandbregions.eu/culture/project/acti vities/cultural_and_creative_industries

[16] Evans, C., Glover, J., Guerrier, Y., \& Wilson, C. (2007) Implementing diversity policies: guiding principles. Equalitec.

[17] Feldman, M. P. (2014). The character of innovative places: entrepreneurial strategy, economic development, and prosperity. Small Business Economics, 43 (1), 9-20.

[18] Florida, R. (2002). The rise of the creative class. The Washington Monthly, 34 (5), 15-25.

[19] Gereffi, G., Humphrey, J., \& Sturgeon, T. (2005). The governance of global value chains. Review of international political economy, 12 (1), 78-104.

[20] Go, R., Acunzo, J., Frankel, K. \& Simon, A. (n.d.). Boston is home to a thriving web and mobile startup ecosystem. Retrieved from bostontechguide: http://bostontechguide.com/

[21] Grootaert, C. (1998). Social Capital: The Missing Link? Washington: The World Bank - Social Development Department - Social Capital Working Paper Series.

[22] Gropas, R., \& Triandafyllidou, A. (2014). Survey report. Emigrating in times of crisis. Highlights and new data from an e-survey on high-skilled emigrants from Southern Europe and Ireland. Global Governance Program, European University Institute. Available online at: http:// globalgovernance programme. eui.

eu/wp-content/uploads/2014/03/SURVEY-REPORT-Emigratin g-in-times-of-crisis. pdf (accessed: 11 October 2016).

[23] Hacin + Associates, Inc. (2014). Seaport Square in Boston's Innovation District. Boston.
[24] Hall, P., \& Pfeiffer, U. (2002). Urban Future 21-a global agenda for twenty-first century cities. International Planning Studies, 7 (2), 177-182.

[25] Hassen, I., \& Giovanardi, M. (2018). The difference of 'being diverse': City branding and multiculturalism in the 'Leicester Model'. Cities, 80, 45-52. doi: 10.1016/j.cities.2017.06.019.

[26] Jacobs, J. (1961). The Death \& Life of Great American Cities.

[27] Jacobs J. (1966) The Economy of Cities.

[28] Johnson, D. (2016). Boston: Teeming with Innovation. Retrieved 2017, from smartmeetings.com: http://www.smartmeetings.com/hotels-resorts/96092/boston-tr avel-teeming-with-innovation

[29] Josefová, A. (2014). The Cultural diversity as a phenomenon of the multicultural society. Procedia-Social and Behavioral Sciences, 152, 1019-1021.

[30] Katz, B., \& Wagner, J. (2014). The rise of innovation districts: A new geography of innovation in America. Metropolitan Policy Program at Brookings, May.

[31] Landry, C. (2011). Creativity, Culture \& the City: A question of interconnection. In Report. Forum D'Avignon Ruhr, Germany, ECCE.

[32] LeMay, M. C. (Ed.). (2012). Transforming America: Perspectives on US Immigration [3 volumes]: Perspectives on US Immigration (Vol. 1). ABC-CLIO.

[33] Leung, A. K. Y., Maddux, W. W., Galinsky, A. D., \& Chiu, C. Y (2008). Multicultural experience enhances creativity: the when and how. American Psychologist, 63 (3), 169.

[34] Lucas, R. E. (1988). On the mechanics of economic development. Journal of monetary economics, 22 (1), 3-42.

[35] Marshall, A. (1927). Principles of economics: an introductory volume.

[36] MassDot (2015). South Boston Waterfront Sustainable Transportation Plan. Boston.

[37] Merk, O. (2013). The competitiveness of global port-cities: synthesis report. OECD Regional Development Working Papers, 2013 (13), 0_1.

[38] Metcalfe, S. \& Ramlogan, R. (2008). Innovation systems and the competitive process in developing economies, The Quarterly Review of Economics and Finance, Vol. 48, No. 2, pp 433-446.

[39] Moen, A., Mørch, A. I., \& Paavola, S. (Eds.). (2012). Collaborative knowledge creation: Practices, tools, concepts (Vol. 7). Springer Science \& Business Media.

[40] OECD (1996), The Knowledge-Based Economy, Head of Publications Service, Paris. DOI: https://www.oecd.org/sti/sci-tech/1913021.pdf

[41] OECD. (2007). Innovation and Growth Rational for an Innovation Strategy. [online] Luxemburg: Statistical Office of the European Communities. Available at: http://www.oecd.org/sti/inno/39374789.pdf [Accessed 03 Feb. 2017].

[42] OECD (2014). The Competitiveness of Global Port-Cities, OECD Publishing, Paris. DOI: http://dx.doi.org/10.1787/9789264205277-en 
[43] Periac, F. (2013). Cultural Diversity, Social Capital and Innovative capacity of Region-Industries.

[44] Porter, M. E. (1990). The competitive advantage of nations. Harvard business review, 68 (2), 73-93.

[45] Porter, M. E. (1998). Clusters and the new economics of competition (Vol. 76, No. 6, pp. 77-90). Boston: Harvard Business Review.

[46] Power, S., Cousins, A., England, S., Brown, C. - ARUP (2015). Greentech in the City - Whitepaper. Bristol.

[47] Rob Hand, Ruediger Eichin, Reiner Bildmayer, \& Stephanie Overby (2015). A New Industrial Revolution: The Innovation Economy and Manufacturing. Retrieved from http://www.digitalistmag.com.

[48] Rodriguez, H., Congdon, D. \& Ampelas, V. (2015). The Development Of Boston's Innovation District: A Case Study of Cross-Sector Collaboration and Public Entrepreneurship.

[49] Romer, P. M. (1990). Endogenous technological change. Journal of political Economy, 98 (5, Part 2), S71-S102.

[50] Rosentraub, M. S. (2014). Reversing Urban Decline: Why and How Sports, Entertainment, and Culture Turn Cities into Major League Winners. CRC Press.

[51] Sassen, S. (2011). Cities in a world economy. Sage Publications.

[52] Sassen, S. (2014). Expulsions. Harvard University Press.

[53] Schumpeter, J. (1942). Creative destruction. Capitalism, socialism and democracy, 825.

[54] Segal, R. (n.d.). Mediterranean Port Cities. Retrieved from http://rafisegal.com

[55] Singer, A. (2015). Metropolitan immigrant gateways revisited, 2014. Metropolitan Policy Program at Brookings. Washing-ton, DC.

[56] Solow, R. M. (1999). Neoclassical growth theory. Handbook of macroeconomics, 1, 637-667.
[57] Storring, N., \& Walker, M., (2016, 05 10). 8 Placemaking Principles for Innovation Districts. Retrieved 2016, from Project for Public Spaces:

https://www.pps.org/blog/eight-placemaking-principles-for-in novation-districts/

[58] The World Bank. (2010). Innovation Policy: A guide for developing Countries. [online] Washington, D.C.: World Bank Group. Available at:

https://openknowledge.worldbank.org/bitstream/handle/10986 /2460/548930PUB0EPI11C10Dislosed061312010.pdf [Accessed 10 Oct. 2016].

[59] Unesco. (2002). Universal declaration on cultural diversity: a vision; a conceptual platform; a pool of ideas for implementation; a new paradigm; a document of the World Summit on Sustainable Development, Johannesburg, 26 August-4 September 2002. K. Stenou (Ed.).

[60] United Nations System-Wide Earthwatch, (n.d.). Oceans and Coastal Areas. Retrieved September 20, 2016, from earthwatch.unep.net:

$\mathrm{http} / /$ earthwatch.unep.net/oceans/coastalthreats.php

[61] Urban Land Institute. (2015). Bay Area Catalysts for Technology Innovation. (p. 71).

[62] Warda, B., Jasper, E. \&Peter, S. (2020). Re-imagining the city: branding migration-related diversity. Published online. Retrieved December 11, 2020, from: https://www.tandfonline.com/doi/full/10.1080/09654313.2019 .1701290 .

[63] Weiler, A. (2006). Companies and workers benefit from diversity policies. Retrieved from https://www.eurofound.europa.eu/observatories/eurwork/articl es/companies-and-workers-benefit-from-diversity-policies

[64] Wood, P., Landry, C., \& Bloomfield, J. (2006). Cultural diversity in Britain: a toolkit for cross-cultural co-operation. York: Joseph Rowntree Foundation.

[65] Yigitcanlar, T. (2011). Moving Towards a Knowledge City? International Journal of Knowledge-Based Organizations (IJKBO), 1 (3), pp. 22-38. 